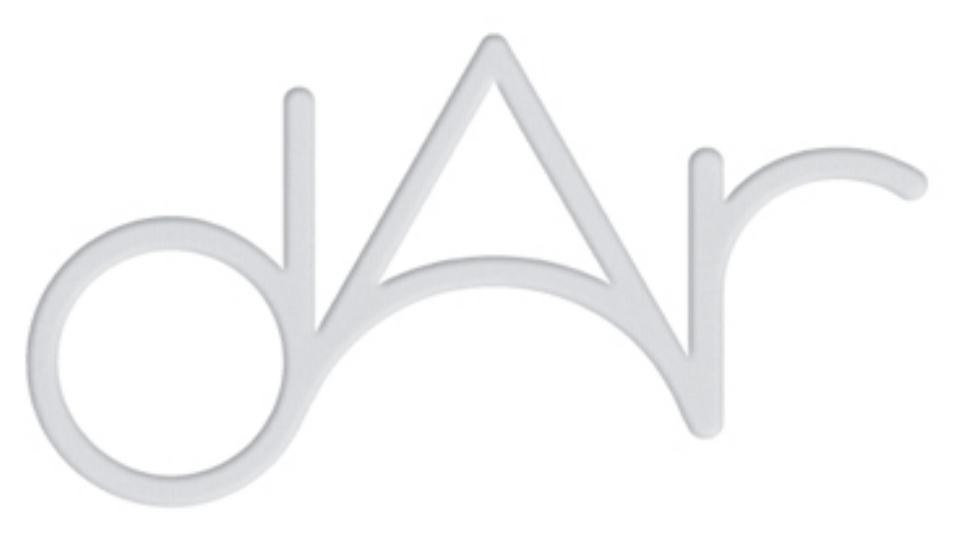

\title{
A Taipa de Mão em Teresina, Piauí, Brasil: a Improvisação e o Uso de Procedimentos Construtivos
}

\author{
Autor(es): $\quad$ Lopes, Wilza Gomes Reis; Carvalho, Thaís Márjore Pereira de; Matos, \\ Karenina Cardoso; Alexandria, Sandra Selma Saraiva de
}

Publicado por: CEAUCP

URL persistente:

URl:http://hdl.handle.net/10316.2/9130

Accessed : $\quad$ 26-Apr-2023 14:30:27

A navegação consulta e descarregamento dos títulos inseridos nas Bibliotecas Digitais UC Digitalis, UC Pombalina e UC Impactum, pressupõem a aceitação plena e sem reservas dos Termos e Condições de Uso destas Bibliotecas Digitais, disponíveis em https://digitalis.uc.pt/pt-pt/termos.

Conforme exposto nos referidos Termos e Condições de Uso, o descarregamento de títulos de acesso restrito requer uma licença válida de autorização devendo o utilizador aceder ao(s) documento(s) a partir de um endereço de IP da instituição detentora da supramencionada licença.

Ao utilizador é apenas permitido o descarregamento para uso pessoal, pelo que o emprego do(s) título(s) descarregado(s) para outro fim, designadamente comercial, carece de autorização do respetivo autor ou editor da obra.

Na medida em que todas as obras da UC Digitalis se encontram protegidas pelo Código do Direito de Autor e Direitos Conexos e demais legislação aplicável, toda a cópia, parcial ou total, deste documento, nos casos em que é legalmente admitida, deverá conter ou fazer-se acompanhar por este aviso.

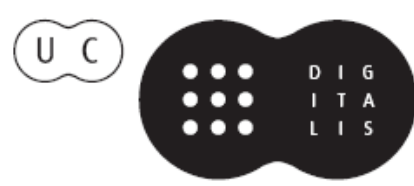


$6^{\circ}$ Seminário de Arquitectura em Terra em Portugal ( $6^{\circ}$ ATP) $9^{\circ}$ Seminário Ibero-americano de Construção e Arquitectura com Terra (9 SIACOT)

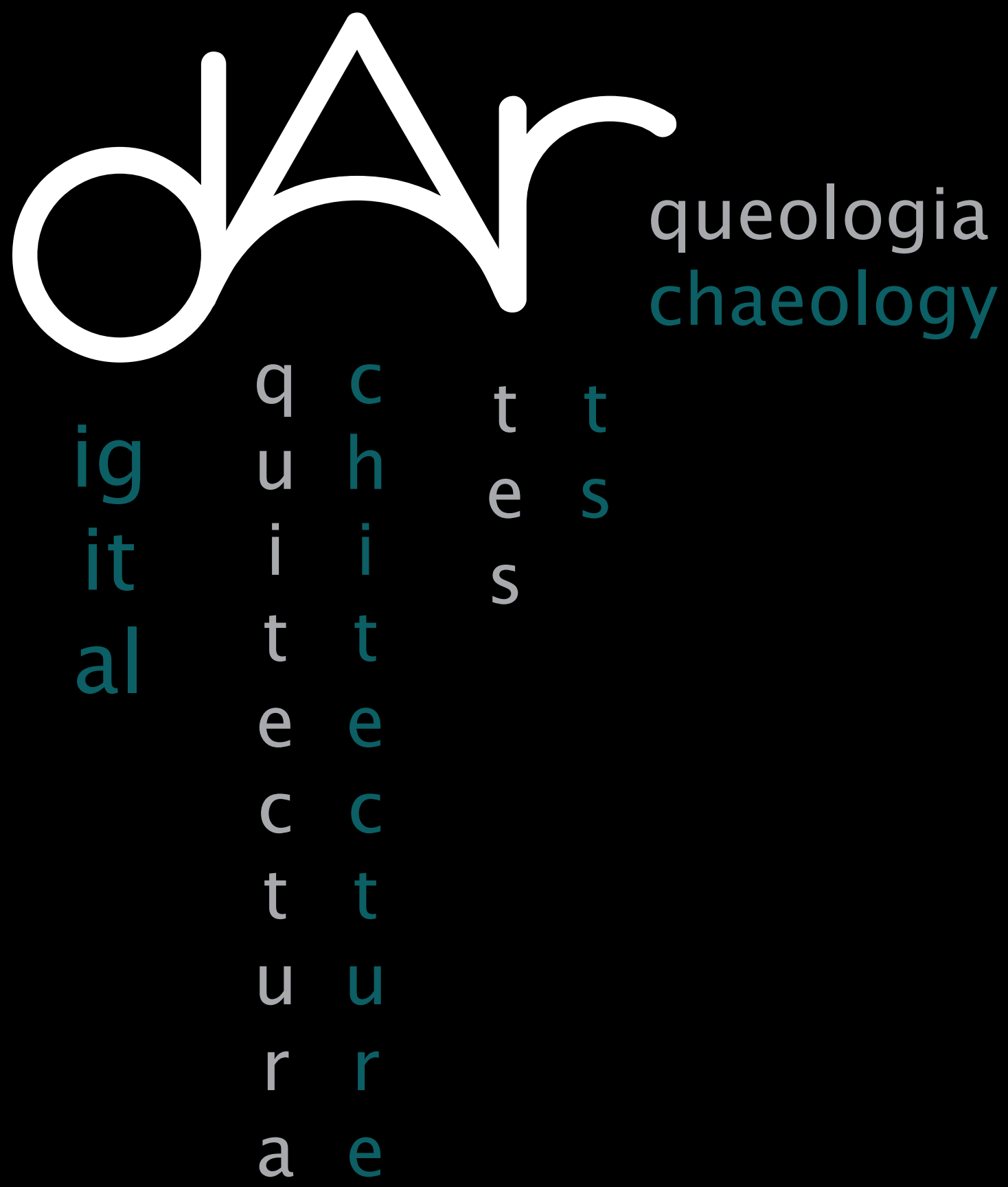




\title{
A TAIPA DE MÃO EM TERESINA, PIAUÍ, BRASIL: A IMPROVISAÇÃO E O USO DE PROCEDIMENTOS CONSTRUTIVOS
}

\author{
Wilza Gomes Reis Lopes* (Brazil) \\ Departamento de Construção Civil e Arquitetura, Universidade Federal do Piauí \\ Thaís Márjore Pereira de Carvalho (Brazil) \\ Departamento de Construção Civil e Arquitetura, Universidade Federal do Piauí \\ Karenina Cardoso Matos (Brazil) \\ Departamento de Construção Civil e Arquitetura, Universidade Federal do Piauí \\ Sandra Selma Saraiva de Alexandria (Brazil) \\ Departamento de Construção Civil e Arquitetura, Universidade Federal do Piauí
}

\section{RESUMO}

A arquitetura de terra chegou ao Brasil, durante a colonização, trazida pelos portugueses, destacando-se, como técnicas construtivas mais utilizadas, o adobe, a taipa de pilão e taipa de mão ou pau-a-pique. Tais métodos foram bastante difundidos e estão presentes em muitos estados do país. Bastante utilizadas durante o período colonial foram esquecidas e abandonadas, após a chegada dos novos materiais, ficando restritas às aulas de história da arquitetura e consideradas ultrapassadas e sem durabilidade. A cidade de Teresina que foi criada em 1852 para ser a capital de Piauí, estado da região Nordeste do Brasil, apresentou a partir de 1970, grande crescimento populacional, recebendo habitantes provenientes das zonas rurais e interioranas, à busca de emprego e de melhores condições de vida. Muitas vezes sem terem acesso ao processo de produção formal de moradia, recorrem à invasão de áreas ociosas e à autoconstrução de habitações. Sendo assim, é comum encontrar casas de taipa de mão, construídas em terrenos vazios, às margens dos rios ou em áreas de risco, em vários bairros da cidade. Tais edificações, construídas rapidamente, com o intuito de ocupar o espaço, estando associadas a processos sociais transitórios e realizadas sem os devidos cuidados técnicos, resultam, na maioria das vezes, em construções precárias, que desestimulam o uso desta técnica construtiva. Os preconceitos para com a eficiência das técnicas de construção com terra são infundados, observando-se que elas poderiam ser uma alternativa para amenizar o atual déficit habitacional brasileiro, desde que fossem usados os procedimentos corretos.

Esta técnica foi bastante usada no Brasil, encontrando-se exemplares em todo país, devido a diversas razões, tais como: facilidade de sua construção, não necessitando de mão-de-obra especializada, rapidez e economia na execução, além de ser leve e de facilmente adaptar-se às topografias acidentadas. Vários exemplos de construção em taipa de mão, por exemplo, construídos em tempos remotos, persistem até nossos dias, desafiando às intempéries e ao próprio tempo, demonstrando o potencial de seu uso e de sua durabilidade, além de várias construções contemporâneas existentes no país. A importância da preservação destas técnicas não se vincula apenas a aspectos históricos e culturais, mas, fundamentalmente, à potencialidade que apresentam como alternativas para a construção. Portanto, é importante a divulgação de edificações devidamente executadas, que possam demonstrar a durabilidade, a versatilidade e a viabilidade da arquitetura de terra, podendo se configurar como uma alternativa para a redução do déficit habitacional brasileiro.

A presente comunicação tem como objetivo identificar o uso da taipa de mão na cidade de Teresina e avaliar esta técnica construtiva, comparando construções existentes, realizadas sem os devidos cuidados técnicos, com os parâmetros técnicos corretos de construções com terra.

Palavras-chave: Habitação, material alternativo, taipa de mão. 


\section{A ARQUITETURA DE TERRA}

A importância da arquitetura construída com terra é percebida por diferentes aspectos, seja pelo ponto de vista histórico e antropológico, ou ainda, pela sua larga utilização como material básico em regiões onde há escassez de recursos naturais (Ramos, Gámez, Cossío, 2002, p. 7).

O emprego da terra para a construção de edificações trata-se de uma prática milenar, presente nas técnicas construtivas das mais diversas sociedades. Minke (2001, p. 13) afirma que na Turquia, na Assíria e em outros lugares do Oriente Médio foram encontradas construções com terra apiloada ou moldada, datando de entre 9000 e 5000 a.C. Dethier (1982, p.7) afirma que, desde a antiguidade a terra foi bastante utilizada, por várias civilizações, na Mesopotâmia, Egito, também na Europa, na África, no Oriente médio, pelos romanos, muçulmanos e na China, entre outras, podendo-se afirmar que, atualmente, mais de um terço da população mundial vive em construções de terra crua.

Utilizada em vários locais do mundo e sob diversas formas, a arquitetura de terra chegou ao Brasil, durante a colonização, trazida pelos primeiros colonizadores portugueses, destacando-se, como as técnicas construtivas mais utilizadas, o adobe, a taipa de pilão e taipa de mão ou pau-a-pique. De acordo com Milanez (1958), os nativos locais não usavam a terra para construir, desconhecendo tais técnicas, antes da chegada dos portugueses. Seus abrigos eram de madeira, paus roliços e vedações de palha e folhagens. Além dos portugueses, os africanos trazidos como escravos tinham conhecimento do uso da terra para construções. Tais métodos foram bastante difundidos e estão presentes em muitos estados do país.

Para Del Brenna (1982, p. 196), a terra adotada desde o início da colonização, em todo o território brasileiro, "permaneceu e se desenvolveu quando e onde sua utilização foi confirmada pela experiência do solo e do clima, resultando numa série de soluções de grande singeleza, funcionalidade e perfeita adaptação ao meio". Segundo Souza (1996, p. 114), nas localidades do Brasil onde a pedra era rara e de difícil extração, prevaleceu a arquitetura e construção com terra, sob diversas formas de construção.

O século XIX introduziu processos industriais, que contribuíram para o desenvolvimento de diversos segmentos relacionados à transformação de matérias primas em produtos manufaturados, o que resultou no surgimento de materiais amplamente utilizados nos dias atuais. Na construção civil, o uso da tecnologia fez com que muitos dos meios de produção artesanais presentes até então, aos poucos, fossem sendo abandonados, substituídos por materiais e procedimentos que viriam a se universalizar. Porém, apesar do preconceito, atualmente há, em todo o mundo, uma crescente aceitação às formas alternativas de edificação, com as chamadas ecotécnicas e a arquitetura sustentável, em que a construção com terra está inserida.

Nas primeiras construções no interior do Piauí, estado da região nordeste do Brasil, foram utilizadas as técnicas da taipa de mão, do adobe e da taipa de pilão, destacando-se a taipa de pilão para as casas de fazenda e de engenho. Na zona urbana, também foi utilizada a terra para construção, como registram algumas edificações históricas, do século XVIII, ainda existentes em várias cidades do Piauí. Como exemplo, podem ser citadas as Igrejas de Nossa Senhora do Rosário e de Nossa Senhora da Vitória, executadas com taipa de pilão e o antigo Círculo Militar, construído em adobe, na cidade de Oeiras e o Hotel Pousada Velho Monge, na cidade de Amarante, executado em adobe.

Além disso, em alguns municípios, continuase a utilizar, em construções mais recentes, o adobe e a taipa de mão, como por exemplo, nas cidades de Uruçuí e de Assunção do Piauí. Nesta última, cerca de mais de $90 \%$ de suas construções são executadas em adobe.

No centro da cidade de Teresina, capital do Piauí, ainda é possível encontrar exemplares 
de arquitetura de terra em bom estado de conservação, construídos no século XIX e início do século XX, atestando a qualidade do material e das técnicas empregada, principalmente de adobe (Alexandria, 2006, p. 121).

Além disso, é comum em Teresina o uso de construções com taipa de mão, executadas a partir de um conhecimento empírico proveniente das zonas rurais e, portanto, realizadas sem os devidos cuidados técnicos. Geralmente, estão associadas a processos sociais transitórios em áreas de invasão, resultando, na maioria das vezes, em construções precárias.

\section{ASPECTOS GERAIS DA TAIPA DE MÃO}

A taipa de mão, também conhecida como taipa, taipa de sopapo, taipa de sebe, barro armado ou pau-a-pique, refere-se a uma técnica amplamente difundida e bastante utilizada no Brasil. Esta técnica é chamada de quincha no Peru e Panamá; de bahareque na Venezuela, Colômbia e América Central e estanqueo ou quincha na Argentina e Uruguai (Oteiza, 2002, p.106). De acordo com Vasconcellos (1979, p. 45), consiste em paus colocados perpendicularmente entre os baldrames e os frechais, nele fixados por meio de furos ou pregos. Perpendiculares a estes são colocados outros mais finos, ripas ou varas, tanto de um lado como de outro, amarrados por meio de tiras de couro, prego ou arame, de cipó, barbante de sisal, tucum, imbé, buriti e outros gêneros próprios para cordas. Depois de feita a trama ou armação, a terra misturada à água é jogada e apertada sobre ela, utilizando-se apenas as mãos, o que deu origem ao seu nome.

Muito utilizada em construções rurais, a taipa de mão, também, se fez presente em obras urbanas, tanto nas paredes externas quanto nas internas. Muitas vezes era associada a outras técnicas (adobe e taipa de pilão). O sucesso desta técnica construtiva se deu por inúmeros fatores, dentre eles, Vasconcellos (1979, p. 33) destaca a facilidade de construção. Já Schmidt (1946, p. 137), refere-se à durabilidade, resistência às intempéries e menor custo. Para Alvarenga (1984, p. 31) sua principal vantagem é a rapidez de execução. A leveza e a capacidade de adaptar-se às topografias acidentadas são qualidades lembradas por Souza (1996, p.116). Trata-se de uma técnica versátil, comprovado por sua grande adaptabilidade às condições locais, com a utilização de materiais encontrados na natureza (Lopes e Ino, 2001, p. 9).

Contudo, mesmo após sua larga utilização desde os primórdios da nossa colonização e apesar de estar integrado à nossa cultura, ao longo dos tempos o valor da taipa de mão foi sendo alterado. Atualmente, esta técnica é associada à pobreza e às construções provisórias. Esta discriminação se deve não só à industrialização da construção civil, como à perda de suas características de execução, por falta de conhecimentos apropriados da parte dos construtores. Dessa forma, a maior conseqüência é uma diminuição considerável da qualidade final da obra.

Em contraposição vários exemplos de construção em taipa de mão, construídos em tempos remotos, persistem até nossos dias, desafiando às intempéries e ao próprio tempo, demonstrando o potencial de seu uso, e sua durabilidade. Porém não só exemplos históricos comprovam a viabilidade desta técnica. Diversas construções contemporâneas em taipa de mão, localizadas em várias partes do país, em que foram respeitados procedimentos construtivos adequados, atestam a versatilidade e o excelente desempenho desta técnica. Lopes (1998, pp.128-164), a partir de um levantamento de construções em taipa de mão no Brasil, apresentou diversos exemplos contemporâneos em que foram respeitados procedimentos construtivos adequados e que atestam a versatilidade e o excelente desempenho desta técnica.

Contudo, como qualquer outro material ou técnica, alternativa ou convencional, apresenta vantagens, limitações e características próprias, cujo conhecimento contribui para seu melhor 
desempenho. Para Calla Garcia (2002, p.35), a precariedade das construções com terra resulta da falta de conhecimento cientííco no uso deste material. $O$ autor observa ainda que, o errado conceito de modernidade faz com que se considere o material terra como símbolo de antigo e pobre, associando suas construções à pobreza e ao precário, enquanto que, os materiais como cimento, polímeros e ferro são considerados como símbolos de materiais modernos. Na visão de Souza (1996, p. 115), ocorre que o antigo "saber fazer" tem sido substituído e adulterado, restando hoje, apenas um arremedo do que outrora se praticava.

\section{TERESINA E A PROBLEMÁTICA HABITACIONAL}

O Piaú, estado localizado na região Nordeste do Brasil, tem Teresina, como sua capital, desde agosto de 1852, quando foi fundada para essa finalidade, substituindo a cidade de Oeiras, sua primeira capital. Situada entre dos rios, o Poti e o Parnaíba, apresentando altitude média de 72,00 m, possui, de acordo com a contagem de 2007, uma população de 779.939 habitantes (IBGE, 2007).

A situação atual da cidade apresenta um condições de vida, em relação a trabalho, estudo e, principalmente, atendimento de saúde.

Em meados da década de 1970, teve início o processo do surgimento e adensamento de favelas em Teresina. A princípio, tratavase de pequenos núcleos que se faziam presentes em pontos diversos da cidade, principalmente no Centro, Zona Sul e Zona Norte. Tais núcleos eram compostos por migrantes recém-chegados e/ou famílias já expulsas de outras áreas da cidade, em decorrência das políticas que visavam melhorias em infra-estrutura: construção de avenidas e ruas (Lima, 1996, p.25).

A situação foi se agravando cada vez mais nos anos 1990, em função da chegada de mais pessoas do interior do Estado, além daquelas que eram vítimas de desapropriação dentro da própria Teresina. No entanto, em função dos grandes espaços vazios, frutos da urbanização desarticuladas da cidade, proporcionaram que as favelas não se concentrassem apenas na periferia.

A carência de moradias resultou na produção de edificações executadas em taipa de mão, que produzidas com um objetivo temporário e realizadas sem
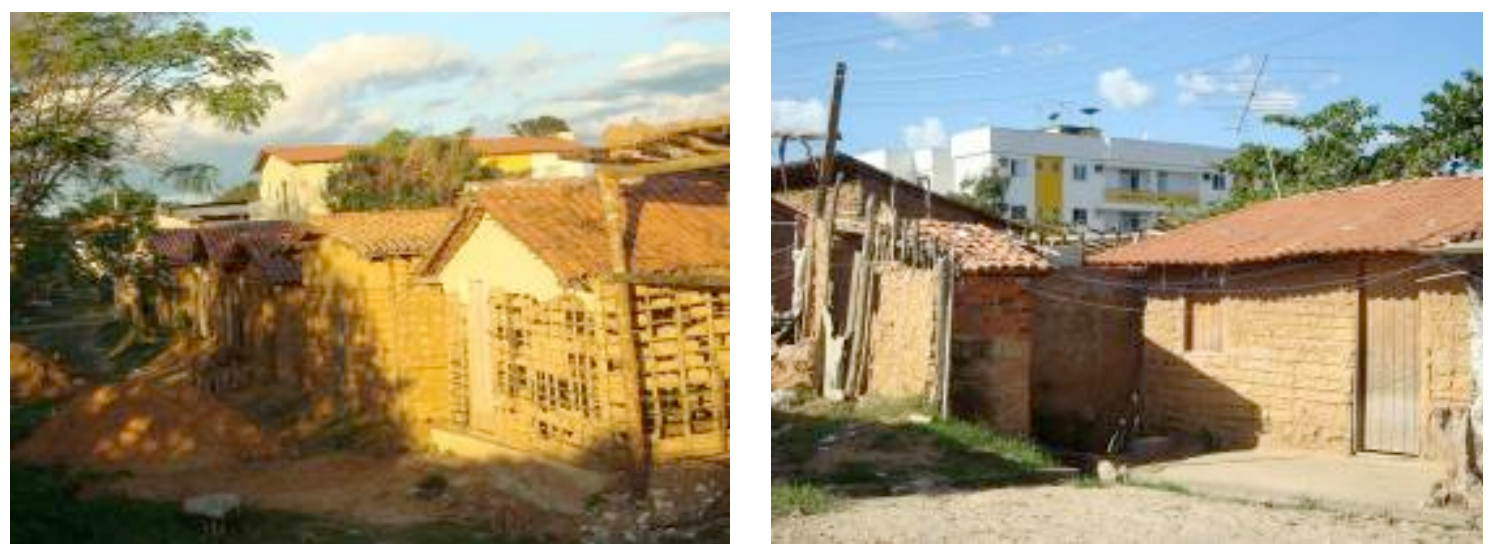

Fig. 1 e 2 - Casas de taipa erguidas em região de risco, próxima ao Rio Poti e em área de conjuntos habitacionais, na Zona Leste de Teresina. (Crédito: Thaís Carvalho, 2009).

déficit habitacional considerável, visto que, a capital representa um pólo de atração para muitos imigrantes, que visualizam em Teresina perspectivas de melhores seguir os procedimentos corretos, deixam a desejar no que se refere a acabamento, durabilidade e aparência. Assim, tornou-se prática comum a construção de casas de 
taipa de mão, em áreas de risco, como nas margens dos rios (Fig. 1) ou terrenos de grande inclinação, impróprios para implantação de construções, leitos de ruas, ou ainda em terrenos desocupados nos bairros nobres da cidade (Fig. 2).

Na maioria das vezes tais construções são executadas em curtíssimos espaços de tempo, com a intenção apenas de ocupar e garantir uma área para habitar. Para (Lima, 2003, p.50), "as formas mais recentes de ocupação apresentam uma tendência de localização próxima aos conjuntos habitacionais, áreas estas que oferecem, em tese, maior acesso a serviços urbanos".

\section{O USO DA TAIPA DE MÃO EM TERESINA}

Em 1996, a Prefeitura Municipal produziu o Censo das Vilas e Favelas de Teresina, constatando que o número de ocupações era de 149 vilas, favelas e áreas de assentamento, com 24.895 domicílios, abrigando 25.775 famílias, e uma população de 94.617 habitantes. Das edificações existentes, 11.692 moradias $(46,97 \%)$ eram construídas de taipa com cobertura de telha e 3311 habitações $(13,29 \%)$ eram de taipa com cobertura de palha, perfazendo o total de 15.003 construções de taipa de mão (Teresina 1996, p.16).

A Prefeitura Municipal de Teresina desenvolve programas voltados para a venda de terrenos urbanizados, em condições facilitadas de financiamento, visando o assentamento de famílias selecionadas (Lotes Urbanizados), ou para atender famílias que ocupam áreas de risco ou conflito potenciais (Banco de Terras Municipais - BTM), entre outros programas municipais. Mas a quantidade de áreas de invasões, em que são construídas novas casas de taipa de mão, continuar a crescer. Foi constatado, em levantamento de 2005, um total de 129 Vilas e Favelas distribuídas entre as cinco zonas da cidade, relacionadas na Tabela 1.

São encontradas em todas as zonas da cidade, principalmente Zona Sudeste, na Zona Leste, como esta construção localizada na Vila Cidade Leste (Fig. 3) e na Zona Norte, como pode ser constatado pelas habitações existentes em áreas invadidas no bairro Aeroporto (Fig. 4).

Tais construções são executadas, muitas vezes, pelos próprios moradores, com materiais disponíveis no próprio local da construção. E, por isso, adquirem problemas funcionais e estéticos, relacionados não só à má execução, mas também à falta de conhecimento sobre os métodos corretos de se construir com terra, especificamente com a taipa de mão.

A análise de algumas dessas construções executadas em taipa de mão, revelou alguns problemas que são comuns a todos os casos. Em sua grande maioria, as moradias foram construídas sem preocupação com a fundação, e utilizando a madeira de má qualidade. O telhado quase sempre é curto e desalinhado, o que não confere proteção às paredes em relação à umidade $\mathrm{O}$ barreamento das paredes é feito esporadicamente, sem levar em consideração impermeabilização ou

\begin{tabular}{ccc}
\hline ZONA DE TERESINA & N $^{\circ}$ DE VILAS/ FAVELAS & N $^{\circ}$ DE HABITAÇÕES \\
\hline \hline Zona Norte & 53 & 3228 \\
Zona Sul & 30 & 2275 \\
Zona Sudeste & 22 & 1564 \\
Zona Leste & 24 & 3610 \\
TOTAL & $\mathbf{1 2 9}$ & $\mathbf{1 0 . 6 7 7}$ \\
\hline
\end{tabular}

Tabela 1. Levantamento das Construções em Taipa de Teresina no ano de 2005 (Fonte: Superintendência de Desenvolvimento Urbano - SDU - Regional Sul. 2005) 

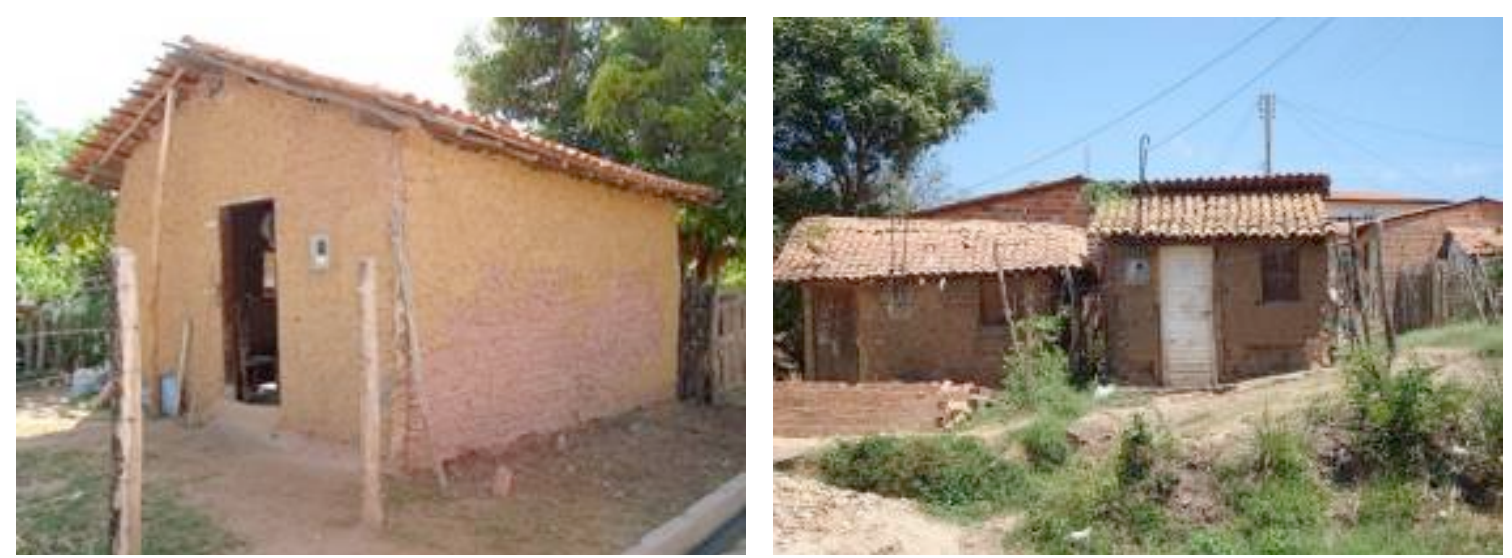

Fig. 3 e 4 - Construções de taipa de mão na Vila Cidade Leste, na Zona Leste e no bairro Aeroporto, Zona Norte de Teresina. (Crédito: Thaís Carvalho, 2009).

nivelamento.

Trata-se de edificações realizadas de maneira provisória pela população carente, produzidas com um objetivo temporário, e executadas sem seguir os procedimentos corretos, pois se configuram como o meio mais rápido e barato para a construção de edificações. Dessa forma deixam a desejar no que se refere ao acabamento, durabilidade e aparência, contribuindo para o fortalecimento da imagem da casa de terra associada à pobreza e às construções provisórias.

Como pode ser observado, é possível encontrar exemplares de casas de taipa de mão, em todas as zonas do perímetro urbano da cidade de Teresina. Pelo número de edificações existentes, percebe-se que esta técnica é de conhecimento de grande parte da população e de fácil execução, podendo representar uma alternativa para a produção de habitações pela população local, desde que seja realizada com materiais e procedimentos apropriados.

\section{PARÂMETROS CONSTRUTIVOS PARA A TAIPA DE MÃO}

Inúmeras construções históricas executadas com terra são encontradas, ainda hoje, perfeitamente conservadas, entretanto é importante executar seguindo certas recomendações. Pinto (1993, p. 614) afirma que a maior ameaça à conservação das edificações de terra são as infiltrações de água, tanto por capilaridade do solo, quanto por falta de proteção adequada com rebocos mal executados.

Sendo assim, é importante proteger a edificação de terra do contato com a umidade do solo, elevando-a do chão ou utilizando um alicerce, de pedras ou tijolos, devidamente impermeabilizados ou usando cinta de concreto magro. Com o propósito de evitar a incidência direta da chuva, indica-se a utilização de grandes beirais e para conferir solidez, estabilidade e melhor aparência à construção.

Também, não se deve descuidar, durante a execução da obra, do uso de todos os métodos usuais de construção. Independente do tipo de material empregado é sempre necessário que o conjunto estrutural seja sólido e estável, para evitar desaprumos, desnivelamentos e trincas nas paredes, utilizando-se alguns princípios elementares em construção e equipamentos simples, tipo esquadro, prumo e nível (Lopes e Ino, 2003).

Ferraz (1992, p.18) destaca que a pintura, em geral, melhora a salubridade e conservação da habitação, além de tornála agradável visualmente. Para Alvarenga (1984), um dos maiores problemas das habitações de taipa deve-se à falta de revestimento, que é fundamental para a proteção das paredes contra ação de água, bem como para evitar que insetos se alojem nas gretas que surgem depois do barro secar. O reboco é, geralmente, feito com o próprio barro misturado com maior quantidade de areia e aplicado em duas 
Wilza Gomes Reis Lopes, Thaís Márjore Pereira de Carvalho, Karenina Cardoso Matos e Sandra Selma Saraiva de Alexandria

camadas, sendo a primeira, mais áspera, enquanto a segunda camada deve ser com areia mais fina.

Para o preenchimento das paredes potencial e a durabilidade deste tipo de construção.

No bairro Piçarra, da Zona Sul da cidade,
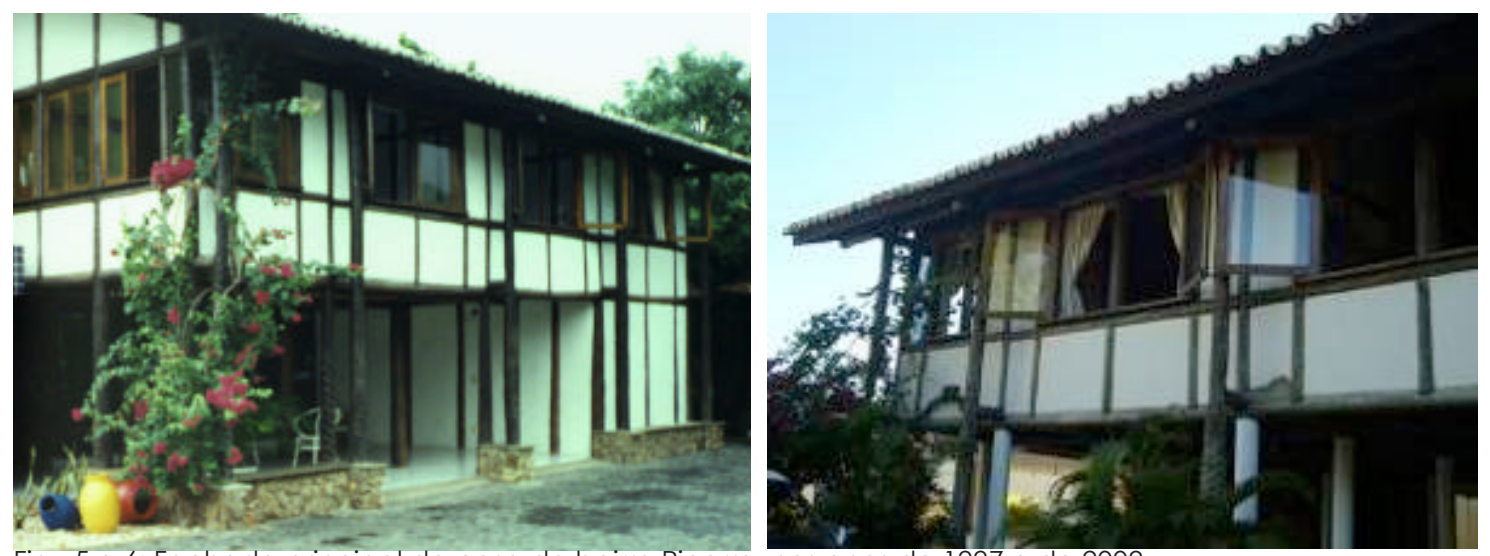

Fig. 5 e 6: Fachada principal da casa do bairro Piçarra, nos anos de 1997 e de 2009.

(Créditos: Wilza Lopes, 1997 e Thaís Carvalho, 2009)

de terra, deve-se aplicar primeiro uma camada de barro (terra e água) forma mais superficial, sem cobrir as ripas, deixando a parede secar, em torno de 15 dias. Em seguida aplica-se a segunda camada, que deve preencher todas as trincas e cobrir as ripas. Depois de seca, aplica-se uma argamassa fina de cimento ou cal, areia e saibro, podendo finalizar com acabamento de pintura ou caiação (Fundação DAM 1988, pp. 47-49). Milanez (1958) chama a atenção para que, durante o barreamento, a terra seja calcada com as mãos entre as varas do entramado e não simplesmente jogada.

Para proteção contra os danos causados pela incidência da água das peças verticais de madeira, pilares e forquilhas, que ficam em contato com o solo, são usados geralmente materiais impermeabilizantes, como pintura asfáltica, betume, resina de fibra de vidro, sacos plásticos e base de concreto, de acordo com a disponibilidade local (Lopes, 1998)

Inúmeras construções históricas, executadas com terra, inclusive dos séculos XVII, XVIII e $X I X$, podem ser encontradas, ainda hoje, em perfeito estado de conservação, como também, edificações contemporâneas, localizadas em diversos locais do Brasil, em que foram utilizados os procedimentos construtivos adequados, comprovando o encontra-se uma residência de alto padrão, projetada pelo arquiteto Paulo Frota, construída em taipa de mão, em 1984, encontrando-se em perfeito estado, conforme imagem de 1997 (Fig. 5) e imagem recente de 2009 (Fig. 6). A construção foi destinada a abrigar uma família, composta de casal e três filhas. $\bigcirc$ projeto original possui cinco quartos, sala única para estar e jantar, lavabo, quatro banheiros, copa-cozinha, despensa, área de serviço, dependência de empregada, varanda e abrigo de carros.

Os pilares, vigas e montantes dos painéis e a estrutura da escada foram executados com a palmeira carnaúba. Além da taipa, foi utilizada a pedra na execução de algumas paredes, como dos banheiros, da caixa d'água e do jardim interno. As paredes em taipa de mão têm espessura de $8 \mathrm{~cm}, \mathrm{com}$ trama de madeira roliça sabiá, na vertical e arame liso $n^{\circ} 18$, dispostos na posição horizontal, distantes $15 \mathrm{~cm}$ entre si.

A edificação passou, recentemente, por algumas reformas, devido a problemas ocorridos nos pilares de carnaúba, substituídos por pilares de concreto, mas nenhuma modificação está relacionada à resistência ou à eficácia das paredes de taipa de mão. Seu proprietário, engenheiro civil Amaury Barbosa, afirmou que os 
gastos em manutenção com a edificação são os comuns a qualquer construção, destacando como mais freqüentes, os reparos no reboco e na pintura.

\section{CONSIDERAÇÕES FINAIS}

Apesar da taipa de mão ter sido abandonada e substituída pelos novos materiais e pelas mudanças tecnológicas surgidas, ainda hoje se continua a construir com taipa, em alguns locais do país, como em Teresina, onde parte da população carente recorre a este processo construtivo para resolver seu problema de abrigo. As más condições da maioria destas construções populares, realizadas sem os devidos cuidados técnicos, resultam em edificações precárias, sem durabilidade e sem qualquer acabamento. No entanto, isto não se deve à ineficiência da técnica, mas sim à forma incorreta como ela é empregada.

Acredita-se que a taipa de mão pode ser mais uma alternativa na solução dos problemas habitacionais, devido à facilidade de execução, inclusive por mão de obra não qualificada, ao excelente desempenho térmico e ao baixo consumo de energia, apresentando resultados excelentes desde que, seguidos os procedimentos técnicos corretos.

\section{Bibliografia}

Alexandria, S. S. S. (2006). Arquitetura e construção com terra no Piauí: investigação, caracterização e análise. (Dissertação Mestrado em Desenvolvimento e Meio Ambiente, Universidade Federal do Piauí UFPI, Teresina).

Alvarenga, M. A. A. (1984). Arquitetura de terra. Técnicas Construtivas. Belo Horizonte. Digitado.

Calla Garcia, A. (2002). La construcción con tierra en la cultura andina. $1^{\circ}$ Seminário Iberoamericano de Construção com Terra, 2002. Salvador, Salvador: Projeto PROTERRA, 27-36.

Del Brenna, G. R. (2002). Para arquitetos e não. In J. Dethier, C. Zbinden (Eds). Arquitetura de terra ou o futuro de uma tradição milenar. Avenir Editora: Rio de Janeiro.
Dethier, J. (2002). A sabedoria da terra. In J. Dethier, C. Zbinden (Eds). Arquitetura de terra ou o futuro de uma tradição milenar. Avenir Editora: Rio de Janeiro.

Ferraz, M C. (1992). Arquitetura rural na Serra da Mantiqueira. São Paulo: Quadrante.

Fundação DAM - Centro de Desenvolvimento das Aplicações de Madeiras no Brasil. (1988). Taipa em painéis modulados. 2. ed. Brasília: MEC/CEDATE.

IBGE - Instituto Brasileiro de Geografia e Estatística. (2007). Cidades. Brasília: IBGE. Acesso em 08/09/2009 em http://www.ibge.com.br/ cidadesat/default.php.

Lima, A. J. (2003). As multifaces da pobreza: formas de vida e representações simbólicas dos pobres urbanos. Teresina: Halley.

Lima, A. J. (1996). Favela COHEBE: Uma história de luta por habitação popular. Teresina: EDUFPI.

Lopes, W. G. R. (1998). Taipa de mão no Brasil: levantamento e análise de construções. Dissertação (Mestrado em Arquitetura, Escola de Engenharia de São Carlos, Universidade de São Paulo, São Carlos, SP).

Lopes, W. G. R., Ino, A. (2003). Aspectos construtivos da taipa de mão. In C. M. Neves, P. C. Salas, R. F. Mellace (Eds). Técnicas mixtas de construcción con tierra, pp. 15-36. PROTERRA/CYTED: Salvador, Brasil.

Lopes, W. G R., Ino, A. (2001). Construções com taipa de mão no Brasil. Revista Baiana de Tecnologia-TECBAHIA, v. 16 ( $\left.n^{\circ} 2\right)$. Camaçari, BA, 7-14.

Minke, G. (2001). Manual de cosntrucción en tierra. 2 ed. Montevideo: Editora NordanComunidad.

Milanez, A. (1958). Casa de terra: As técnicas de estabilização do solo a serviço do homem do campo. Rio de Janeiro: Serviço Especial de Saúde Pública - Ministério da Saúde.

Oteiza, I. (2002). Introducción a La construcción con tierra. In L. M. Ramos, D. R. Gámez, F. V. Cossío (Eds). Arquitectura y construcción con tierra. Tradición e innovación. Introducción. Mairea: Madrid.

Pinto, F. (1993). Arquitectura de terra - Que futuro? . $7^{a}$ Conferência Internacional Sobre o Estudo e Conservação da Arquitectura em Terra. Lisboa: DGEMN, 612-617.

Ramos, L. M., Gámez, D., Cossío, F. V. (Eds). (2002). Arquitectura y construcción con tierra. 
Wilza Gomes Reis Lopes, Thaís Márjore Pereira de Carvalho, Karenina Cardoso Matos e Sandra Selma Saraiva de Alexandria

Tradición e innovación. Introducción. Madrid: Mairea.

Schmidt, C. B. (1946). Construções de taipa. Alguns aspectos de seu emprego e da sua técnica. Boletim de Agricultura, série 47A.

Souza, R. C. J. (1996). Problemas de conservação em construções típicas de Minas Gerais. Cadernos de arquitetura e Urbanismo. Belo Horizonte, $n^{\circ} 4,103-120$.

Teresina. Secretaria Municipal do Trabalho e de Assistência Social. (1996). Censo das vilas e favelas -96. Teresina: Prefeitura Municipal de Teresina.

Vasconcellos, S. (1979). Arquitetura no Brasil: sistemas construtivos. Belo Horizonte: Universidade Federal de Minas Gerais - UFMG.

Agradecimentos

Agradecimentos ao Conselho Nacional de

Pesquisa Conselho Nacional de Desenvolvimento Científico e Tecnológico - CNPq, pelo apoio dado pesquisa: Levantamento e análise de edificações executadas com técnicas de construção com terra no Estado do Piauí (Edital CNPq 061.2005/Processo 401610/2006-3), que deu origem a este trabalho. 